\title{
EVALUASI SIMPANG TAK BERSINYAL JALAN MT. HARYONO - JALAN BANGGERIS MENGGUNAKAN SOFTWARE KAJI
}

\author{
Rusdi Doviyanto \\ Dosen Program Studi Arsitektur Fakultas Teknik \\ Universitas 17 Agustus 1945 Samarinda \\ E-mail : rusdidovi@gmail.com/HP.08125477477
}

\begin{abstract}
ABSTRAK
Simpang tak bersinyal adalah simpang yang paling banyak dijumpai di daerah perkotaan di Indonesia. Apabila kinerja simpang menurun, maka akan menimbulkan kerugian pada pengguna jalan akibat terjadinya penurunan kecepatan, peningkatan tundaan, dan antrian kendaraan. Tujuan dari penelitian ini adalah untuk mengetahui volume lalu lintas perhitungan kinerja simpang tak bersinyal pada Jalan MT. Haryono - Jalan Banggeris, mengetahui kinerja simpang tak bersinyal tingkat pelayanan (level of service/LOS) dan memprediksi tingkat pelayanan (level of service/LOS) simpang tak bersinyal pada Jalan MT. Haryono Jalan Banggeris kondisi 5 (lima) tahun yang akan datang. Metode yang digunakan adalah dengan melakukan pengumpulan data primer dan data sekunder, survey volume lalu lintas dan survey hambatan samping yang kemudian dianalisa berdasarkan MKJI 1997. Hasil penelitian menunjukkan v/c $=0,605<0,85$ dengan arus lalu lintas dengan kapasitas 4104 smp/jam, mempunyai tingkat pelayanan $($ LOS $)=\mathrm{C}$, dimana arus stabil, kecepatan dikontrol oleh arus lalu lintas, pengemudi dibatasi dalam memilih kecepatan.
\end{abstract}

\section{Kata kunci : Simpang Tak Bersinyal, Kinerja, Tingkat Pelayanan}

\section{ABSTRACT}

Unsealed intersections are the most common intersections in urban areas in Indonesia. If the intersection performance decreases, it will cause losses to road users due to decreased speed, increased delays, and vehicle queues. The purpose of this study is to determine the traffic volume calculation of the performance of the unsigned intersection on Jalan MT. Haryono - Jalan Banggeris, knows the performance of the intersection with no signal level of service (level of service I $L O S$ ) and predicts the level of service (level of service / LOS) at the intersection with no signal at Jalan MT. Haryono - Jalan Banggeris condition in the next 5 (five) years. The method used is to collect primary data and secondary data, traffic volume survey and side obstacle survey which is then analyzed based on MKJI 1997. The results showed $v / c=0.605<0.85$ with traffic flow with a capacity of 4104 pcu / hour. , has a service level $(L O S)=C$, where the flow is stable, the speed is controlled by traffic flow, the driver is limited in choosing the speed.

Keywords: Unsigned Intersections, Performance, Service Level 


\section{PENDAHULUAN}

Simpang tak bersinyal adalah simpang yang paling banyak dijumpai di daerah perkotaan di Indonesia. Jenis ini cocok diterapkan jika arus lalu lintas dijalan minor dan pergerakan membelok relatif kecil. Kinerja suatu simpang merupakan faktor utama untuk mengoptimalkan fungsi simpang tersebut dengan parameter mencakup kapasitas, derajat kejenuhan, tundaan dan peluang antrian. Apabila kinerja simpang menurun, maka akan menimbulkan kerugian pada pengguna jalan akibat terjadinya penurunan kecepatan, peningkatan tundaan, dan antrian kendaraan yang mengakibatkan naiknya biaya operasi kendaraan dan menurunnya kualitas lingkungan.

Menurut MKJI (1997) angka kecelakaan pada simpang tak bersinyal diperkirakan sebesar 0,60 kecelakaan/juta kendaraan. Hal ini dikarenakan kurangnya perhatian pengemudi terhadap rambu YIELD (segitiga merah) dan rambu STOP, sehingga mengakibatkan perilaku pengemudi melintasi simpang tak bersinyal tidak menunggu celah dan memaksa untuk memasuki ruas jalan. Permasalahan utama dari simpang ini yaitu adanya konflik kendaraan yang keluar masuk dari jalan utama menuju jalan minor ataupun sebaliknya, juga konflik kendaraan yang melakukan u-turn sehingga mengakibatkan kemacetan lalu lintas dan bahkan berpotensi untuk terjadinya kecelakaan.

Simpang Jl. MT. Haryono - Jl. Banggeris merupakan simpang tak bersinyal. Kondisi simpang ini berpotensi menimbulkan terjadinya kecelakaan dan kemacetan arus lalu lintas, karena kawasan tersebut merupakan salah satu jalan menuju pusat perkantoran dan perekonomian serta didukung dengan kondisi jalan yang berbukit. Konflik kendaraan sering terjadi pada jam-jam sibuk, oleh sebab itu dari konflik yang ada persimpangan ini perlu dikaji kinerjanya, agar dapat menguraikan permasalahannya yang ada.

Tujuan dari penelitian ini adalah untuk mengetahui volume lalu lintas perhitungan kinerja simpang tak bersinyal pada Jalan MT. Haryono - Jalan Banggeris, mengetahui kinerja simpang tak bersinyal tingkat pelayanan (level of service/LOS) dan memprediksi tingkat pelayanan (level of service/LOS) simpang tak bersinyal pada Jalan MT. Haryono - Jalan Banggeris kondisi 5 (lima) tahun yang akan datang.

\section{METODE PENELITIAN}

\section{Lokasi Penelitian}

Kota Samarinda secara astronomis terletak pada posisi antara $117^{\circ} 03^{\prime} 00^{\prime \prime}$ 117 18'14" Bujur Timur dan 00¹9'02" - 0042'34" Lintang Selatan, dengan ketinggian $10.200 \mathrm{~cm}$ diatas permukaan laut. Lokasi simpang yang menjadi objek penelitian ini adalah simpang tak bersinyal pada Jalan MT. Haryono - Jalan Bangggeris Kota Samarinda. 


\section{Metode Kerja}

Metode yang digunakan adalah dengan melakukan pengumpulan data primer dan data sekunder. Pengumpulan data primer dengan cara observasi atau survei secara langsung di lapangan. Data-data yang dikumpulkan meliputi data geometrik persimpangan yaitu lebar jalan, lebar lajur lalu lintas, median, bahu jalan dan volume lalu lintas. Untuk data sekunder diperoleh melalui literature, internet dan dari intansi terkait, meliputi data jumlah penduduk yang digunakan untuk faktor koreksi ukuran kota dan peta lokasi studi. Tahapan analisa simpang tak bersinyal dalam penelitian ini berdasarkan MKJI 1997.

\section{HASIL DAN PEMBAHASAN}

\section{Data Volume Kendaraan}

Data arah pergerakan arus lalu lintas merupakan data yang menjelaskan tentang arah pergerakan lalu lintas pada masing-masing ruas jalan, meliputi arah pergerakan arus lurus (Straight Turn $=\mathrm{ST}$ ), arah pergerakan arus belok kiri (Left Turn $=\mathrm{LT})$, dan arah pergerakan arus belok kanan $($ Right Turn $=\mathrm{RT})$.

Menurut hasil data survei volume kendaraan, jumlah arus lalu lintas cukup tinggi terutama pada lengan Utara yaitu Jalan MT. Haryono dan lengan Barat yaitu Jalan Banggeris didapat jumlah arus (Q) terbanyak yang dipakai sebagai dasar analisis kinerja persimpangan tak bersinyal sebagai berikut :

Untuk jam Puncak adalah :

1. Keluar dari lengan Utara : 2745 Kendaraan/jam

2. Keluar dari lengan Barat : 2539 Kendaraan/jam

Untuk rata-rata adalah :

1. Keluar dari lengan Utara $\quad: 1148$ Kendaraan/jam

2. Keluar dari lengan Barat : 1081 Kendaraan/jam

Data volume kendaraan dapat dibuat pada Gambar 1 berikut ini :

\begin{tabular}{|c|c|c|c|c|c|c|c|c|c|c|c|c|}
\hline \multirow{4}{*}{ 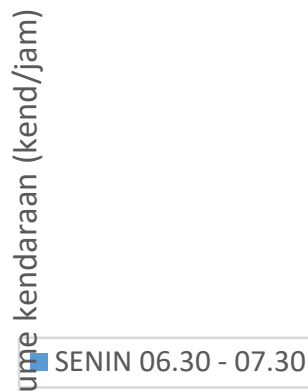 } & \multirow[b]{2}{*}{$\begin{array}{c}\text { Belok } \\
\text { Kiri } \\
(\mathrm{LT})\end{array}$} & \multirow[b]{2}{*}{$\begin{array}{l}\text { Lurus } \\
\text { (ST) }\end{array}$} & \multirow[b]{2}{*}{$\begin{array}{c}\text { Belok } \\
\text { Kanan } \\
\text { (RT) }\end{array}$} & \multirow[b]{2}{*}{$\begin{array}{l}\text { Belok } \\
\text { Kiri } \\
\text { (LT) }\end{array}$} & \multirow[b]{2}{*}{$\begin{array}{c}\text { Lurus } \\
\text { (ST) }\end{array}$} & \multirow[b]{2}{*}{$\begin{array}{c}\text { Belok } \\
\text { Kanan } \\
\text { (RT) }\end{array}$} & \multirow[b]{2}{*}{$\begin{array}{l}\text { Belok } \\
\text { Kiri } \\
\text { (LT) }\end{array}$} & \multirow{2}{*}{\multicolumn{2}{|c|}{\begin{tabular}{c|c} 
Lurus & $\begin{array}{c}\text { Belok } \\
\text { Kanan } \\
\text { (ST) } \\
\text { (RT) }\end{array}$
\end{tabular}}} & \multirow[b]{2}{*}{$\begin{array}{l}\text { Belok } \\
\text { Kiri } \\
\text { (LT) }\end{array}$} & \multirow[b]{2}{*}{$\begin{array}{c}\text { Lurus } \\
\text { (ST) }\end{array}$} & \multirow[b]{2}{*}{$\begin{array}{c}\text { Belok } \\
\text { Kanan } \\
\text { (RT) }\end{array}$} \\
\hline & & & & & & & & & & & & \\
\hline & Kenda & $\begin{array}{c}\text { raan R } \\
\text { (LV) }\end{array}$ & Ringan & Kend & $\begin{array}{r}\text { araan } \\
(\mathrm{HV})\end{array}$ & Berat & Sep & $\begin{array}{r}\text { eda } M \\
\text { (MC) }\end{array}$ & otor & $\begin{array}{l}\text { Kenc } \\
\text { Berm }\end{array}$ & $\begin{array}{l}\text { daraan } \\
\text { notor ( }\end{array}$ & $\begin{array}{l}\text { Tak } \\
\text { (UM) }\end{array}$ \\
\hline & 106 & 40 & 0 & 7 & 7 & 0 & 1165 & 952 & 0 & 2 & 2 & 0 \\
\hline$\overline{\bar{g}}$ SENIN $07.30-08.30$ & 31 & 12 & 0 & 2 & 2 & 0 & 337 & 275 & 0 & 2 & 2 & 0 \\
\hline SENIN $12.00-13.00$ & 10 & 19 & 0 & 0 & 5 & 0 & 91 & 271 & 0 & 0 & 0 & 0 \\
\hline SENIN 16.00 - 17.00 & 24 & 100 & 0 & 6 & 6 & 0 & 253 & 758 & 0 & 0 & 0 & 0 \\
\hline SENIN 17.00 - 18.00 & 10 & 43 & 0 & 3 & 3 & 0 & 109 & 326 & 0 & 2 & 0 & 0 \\
\hline
\end{tabular}

Gambar 1. Grafik Volume Kendaraan Jalan MT. Haryono (Utara)

Pada Hari Senin 
Berdasarkan Gambar 1 di atas diketahui bahwa volume lalu lintas pada hari Senin pukul 06.30 - 07.30 Wita merupakan volume kendaraan yang terbanyak dan pada pukul 12.00 - 13.00 Wita adalah volume kendaraan yang sedikit.

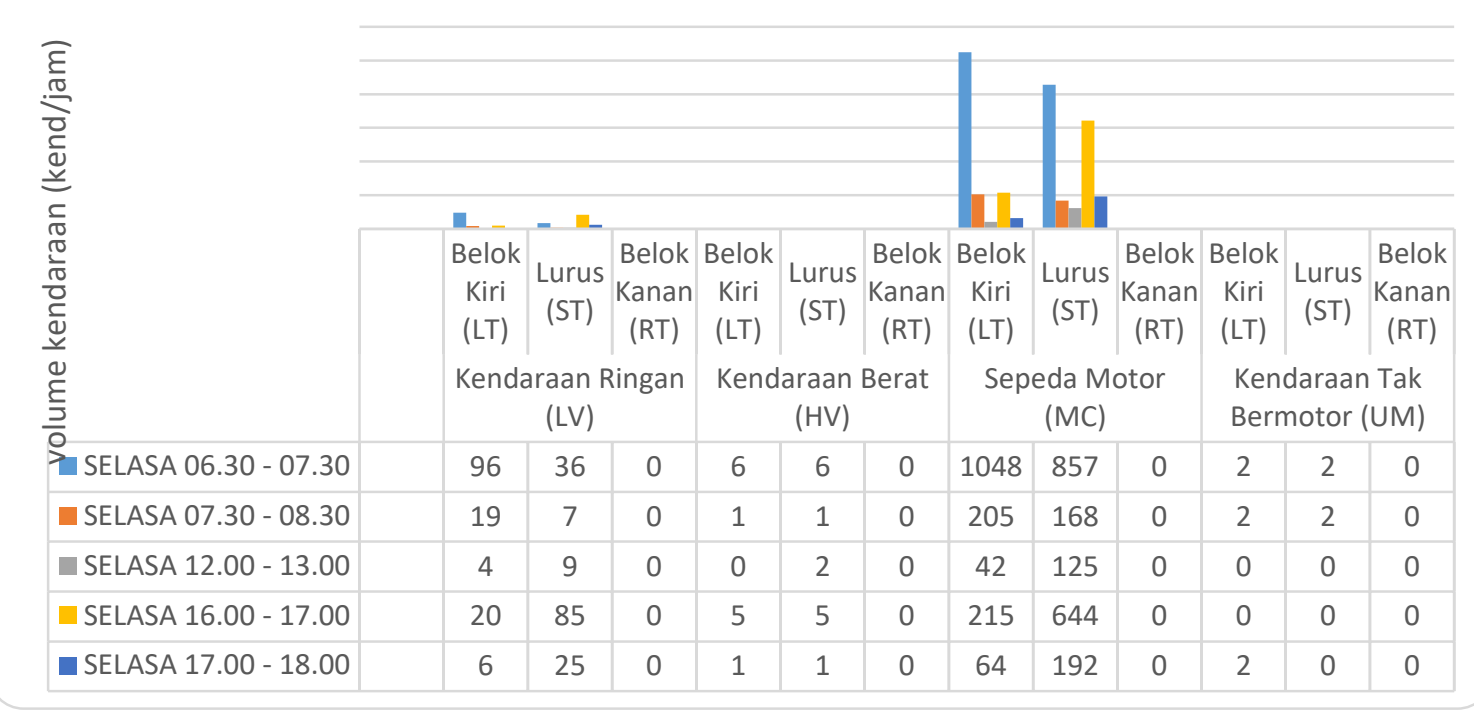

Gambar 2. Grafik Volume Kendaraan Jalan MT. Haryono (Utara) Pada Hari Selasa

Berdasarkan Gambar 2 di atas menunjukkan bahwa volume kendaraan Jalan MT. Haryono (Utara) pada hari Selasa pukul 06.30 - 07.30 Wita adalah volume kendaraan yang terbanyak dan pada pukul 12.00 - 13.00 Wita adalah volume kendaraan yang sedikit.

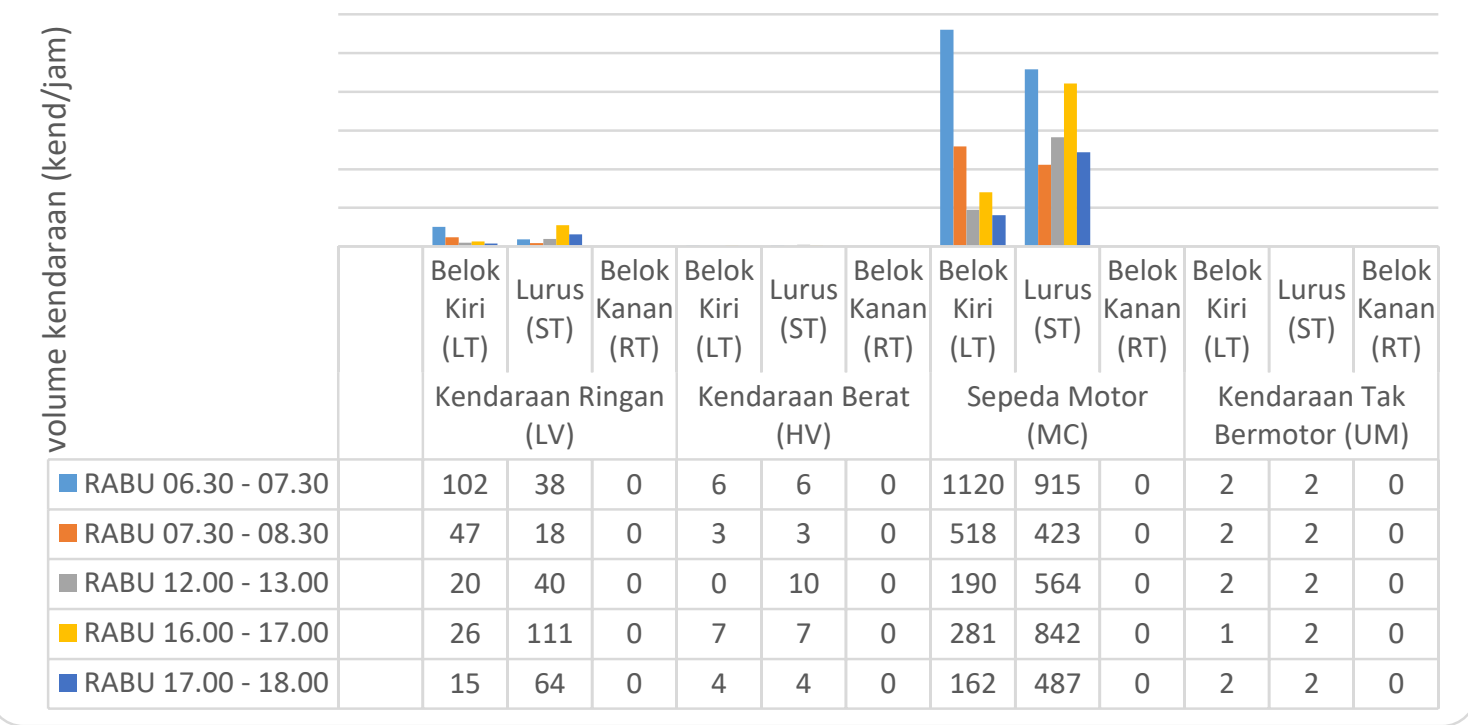

Gambar 3. Grafik Volume Kendaraan Jalan MT. Haryono (Utara) Pada Hari Rabu 
JURNAL KACAPURI

JURNAL KEILMUAN TEKNIK SIPIL

Volume 3 Nomor 2 Edisi Desember 2020

Berdasarkan Gambar 3. di atas bahwa volume kendaraan pada hari rabu pukul 06.30 - 07.30 Wita merupakan volume kendaraan yang terbanyak dan pada pukul $12.00-13.00 \mathrm{Wita}$ adalah volume kendaraan yang sedikit.

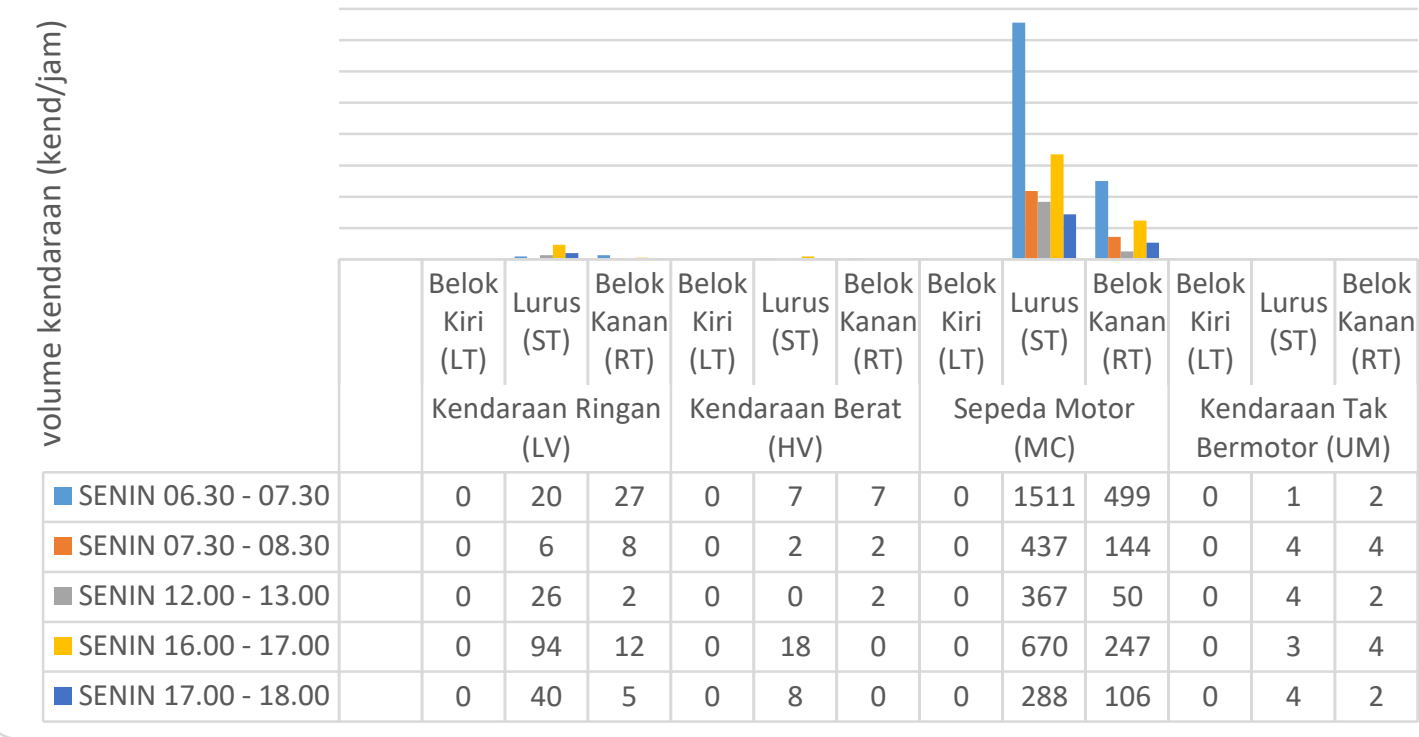

Gambar 4. Grafik Volume Kendaraan Jalan Banggeris (Barat) Pada Hari Senin

Berdasarkan Gambar 4 di atas bahwa volume kendaraan Jalan Banggeris (Barat) pukul 06.30 - 07.30 Wita merupakan volume kendaraan yang terbanyak dan pada pukul 12.00 - 13.00 Wita adalah volume kendaraan yang sedikit.

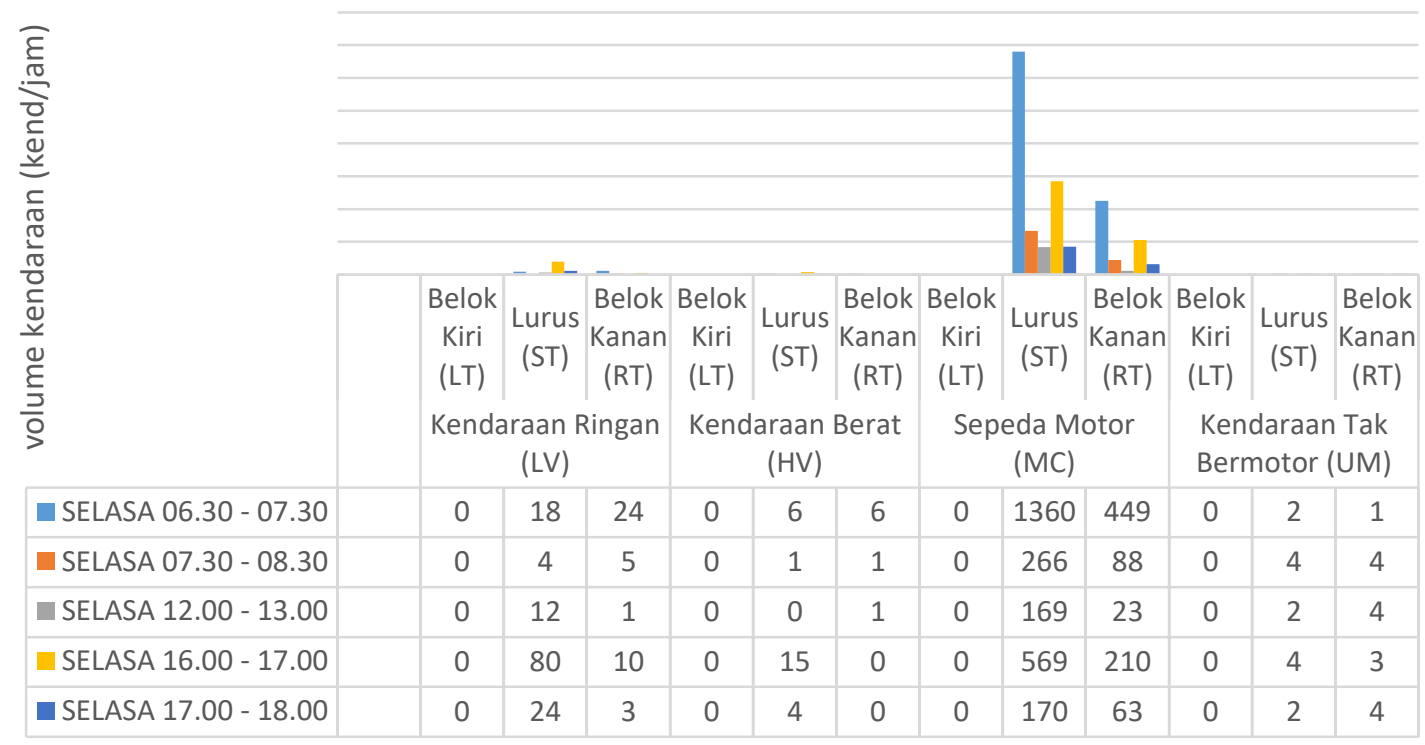

Gambar 5. Grafik Volume Kendaraan Jalan Banggeris (Barat) Pada Hari Selasa 
Berdasarkan Gambar 5. di atas menunjukkan bahwa volume kendaraan Jalan Banggeris (Barat) pada hari selasa pada pukul 06.30 - 07.30 Wita adalah volume kendaraan yang terbanyak dan pada pukul 12.00 - 13.00 Wita adalah volume kendaraan yang sedikit.

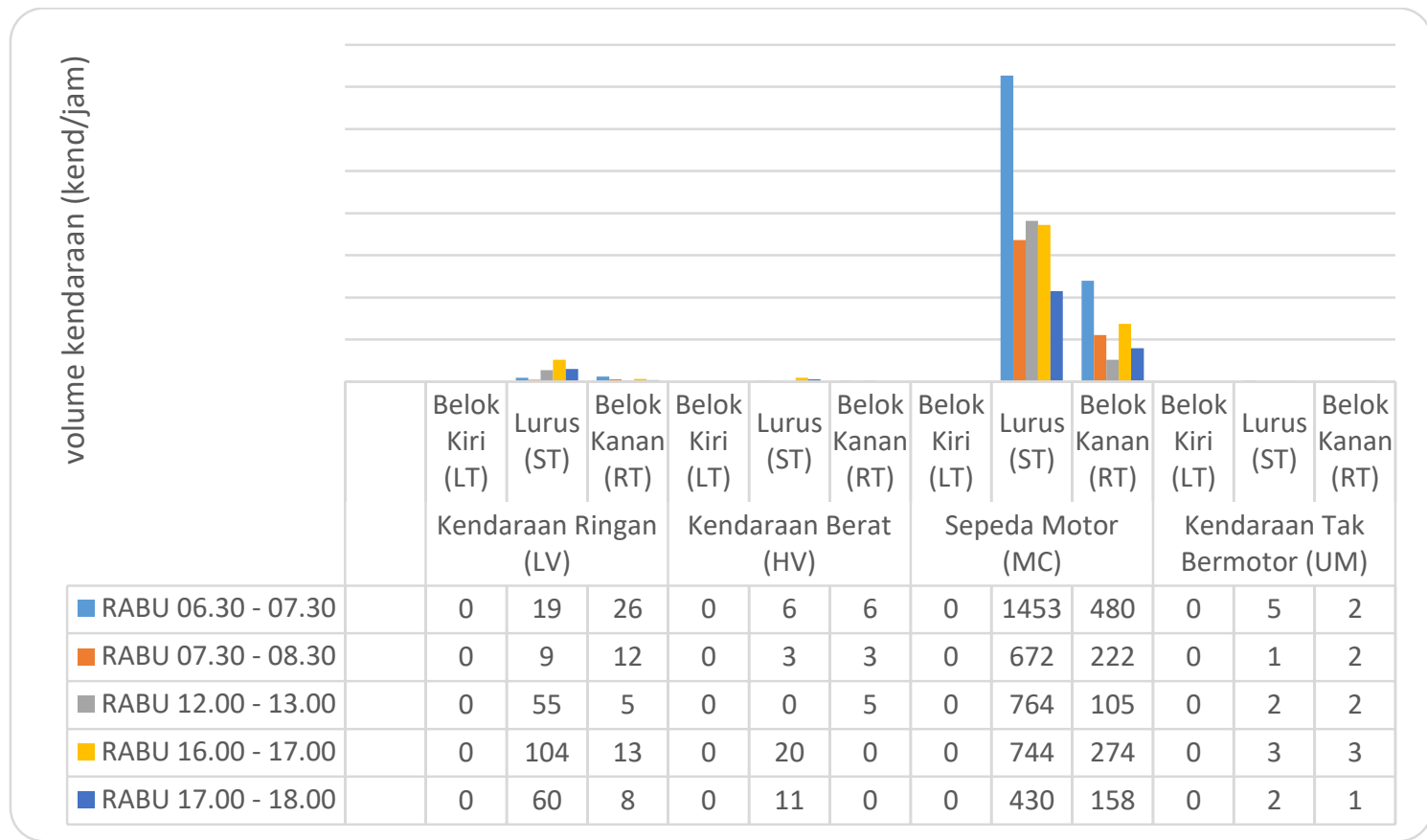

Gambar 6. Grafik Volume Kendaraan Jalan Banggeris (Barat) Pada Hari Rabu

Berdasarkan Gambar 6 di atas menunjukkan bahwa volume kendaraan pada pukul 06.30 - 07.30 Wita adalah volume kendaraan yang terbanyak dan pada pukul 12.00 - 13.00 Wita adalah volume kendaraan yang sedikit.

\section{Geometrik Persimpangan}

Untuk mendapatkan kinerja simpang tak bersinyal meliputi kapasitas (C), derajat kejenuhan (DS), tundaan (D) dan peluang antrian (QS) maka harus memberikan gambaran informasi selengkapnya tentang kondisi persimpangan dan volume lalulintas dibuat arah dan disertakan banyaknya kendaraan dalam pergerakan. Jalan Mayor atau jalan utama adalah jalan yang dipertimbangkan sebagai terpenting pada suatu simpang, misalnya suatu jalan dengan klasifikasi fungsional tertinggi dengan diberi notasi pendekat A dan Pendekat C, sedangkan Jalan Minor diberi notasi pendekat B dan Pendekat D. Pemberian notasi dibuat searah jarum jam. Data kondisi geometrik persimpangan Jalan MT. Haryono - Jalan Banggeris di Kota Samarinda.

1. Lebar Badan jalan di kaki simpang Jalan MT. Haryono $=7,70$ meter $\mathrm{x} 2=$ 15,4 meter.

2. Lebar Badan jalan di kaki simpang Jalan Banggeris $=7,00$ meter 


\section{Analisis Simpang Tak Bersinyal menggunakan software KAJI}

Berdasarkan data yang telah dikumpulkan, kemudian dilakukan analisis kinerja simpang tak bersinyal dengan menggunakan Perangkat Software KAJI untuk persimpangan Jalan MT. Haryono - Jalan Banggeris. Perangkat lunak (program) KAJI adalah penerapan dari MKJI yang terkumpul dalam proyek HCM fase III. Program tersebut benar-benar sesuai dengan manual. KAJI melakukan pemeriksaan masukan, tetapi jika masukan tidak tersedia, maka nilai normal akan digunakan. Hal ini tidak selalu sesuai dengan keinginan kita. Maka dari itu usahakan mendapat data selengkap mungkin sebelum melakukan analisis dan memasukkan data lapangan. Berdasarkan hasil Perangkat lunak (program) KAJI, maka akan didapat keluaran hasil perhitungan untuk simpang tak bersinyal Jalan MT. Haryono - Jalan Banggeris di Kota Samarinda sebagai berikut:

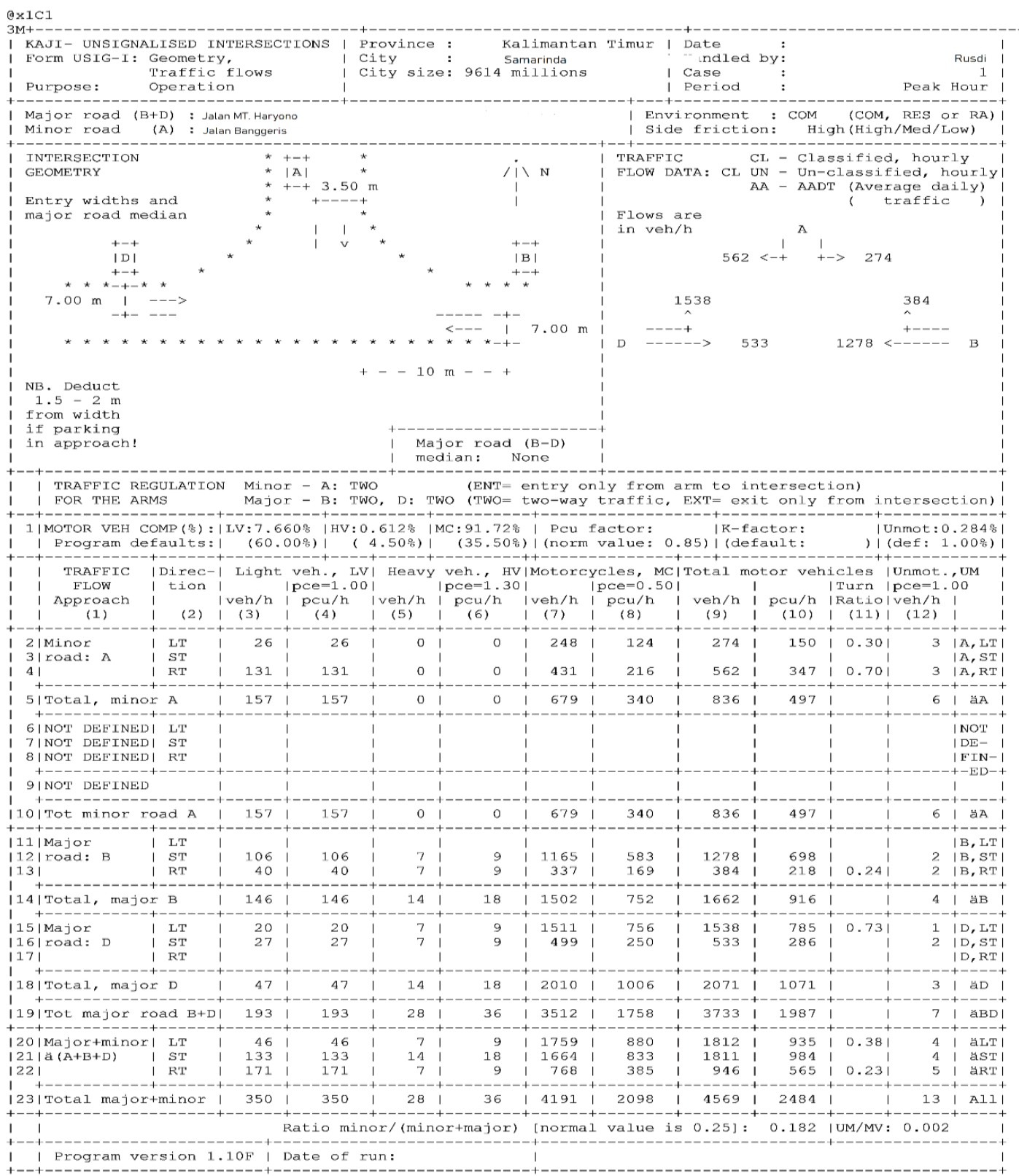


JURNAL KACAPURI

JURNAL KEILMUAN TEKNIK SIPIL

Volume 3 Nomor 2 Edisi Desember 2020

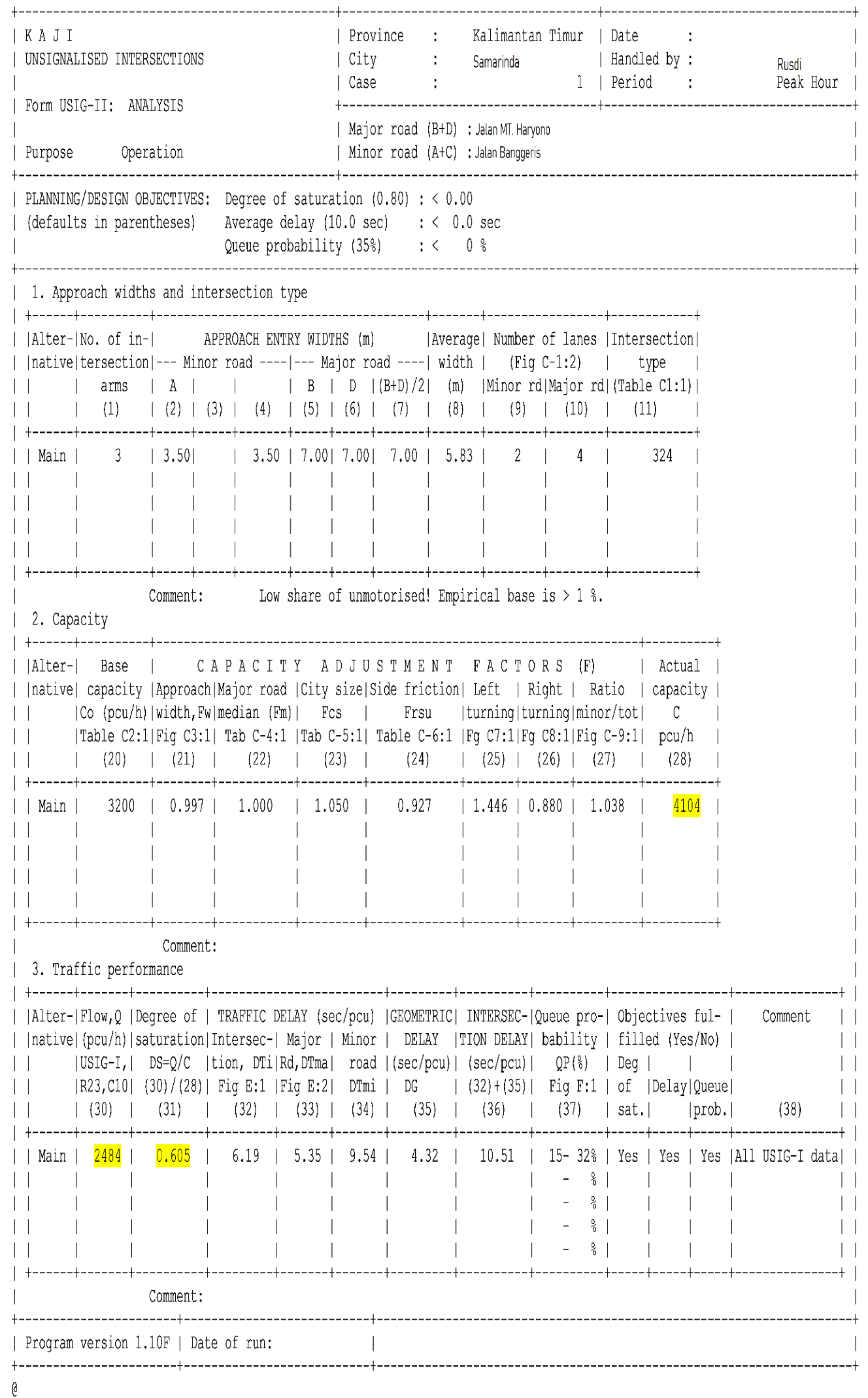




\section{Hasil Analisis Jam Puncak Simpang Tak Bersinyal}

Berdasarkan hasil analisis jam puncak simpang tak bersinyal Jalan MT. Haryono - Jalan Banggeris di Kota Samarinda, diperoleh yaitu sebagai berikut :

\section{Kapasitas $(\mathbf{C})$}

Nilai kapasitas $(\mathrm{C})=4104 \mathrm{smp} / \mathrm{jam}$

\section{Kinerja Lalu lintas}

Kinerja lalu lintas pada persimpangan tak bersinyal meliputi Derajat kejenuhan (DS), Tundaan rata-rata (D), peluang antrian dapat direkapitulasi pada Tabel 1. berikut :

Tabel 1. Kondisi Jam Puncak Kinerja lalu lintas simpang tak bersinyal Jalan MT. Haryono - Jalan Banggeris di Kota Samarinda

\begin{tabular}{|c|c|c|c|c|c|c|}
\hline $\begin{array}{c}\mathbf{Q} \\
\text { (smp/jam) }\end{array}$ & $\begin{array}{c}\mathbf{C} \\
(\mathbf{s m p} / \mathbf{j a m})\end{array}$ & $\begin{array}{c}\mathbf{D S}= \\
\mathbf{Q} / \mathbf{C}\end{array}$ & $\begin{array}{c}\mathbf{D} \\
\text { (dtk/smp) }\end{array}$ & $\begin{array}{c}\mathbf{D}_{\mathbf{M A}} \\
\text { (dtk/smp) }\end{array}$ & $\begin{array}{c}\mathbf{D}_{\mathbf{M I}} \\
(\mathbf{d t k} / \mathbf{s m p})\end{array}$ & $\mathbf{Q P}$ \\
\hline 2484 & 4104 & 0,605 & 6,19 & 5,35 & 9,54 & 10,51 \\
\hline
\end{tabular}

Hasil rasio v/c pada berdasarkan tabel tingkat pelayanan dari Morlok, maka pada kinerja eksisting simpang tak bersinyal Jalan MT. Haryono - Jalan Banggeris di Kota Samarinda, didapat v/c $=0,605<0,85$ mempunyai tingkat pelayanan (LOS) $=\mathrm{C}$, dimana arus stabil, kecepatan dikontrol oleh arus lalu lintas, pengemudi dibatasi dalam memilih kecepatan.

\section{Prediksi Persimpangan Tak bersinyal 5 Tahun yang Akan Datang}

Prediksi kemampuan simpang tak bersinyal Jalan MT. Haryono - Jalan Banggeris di Kota Samarinda yang akan datang dengan menggunakan metode eksponensial dapat dihitung sebagai berikut :

Jika diketahui ;

Volume arus lalulintas tahun $2019 \quad(\mathrm{Po}) \quad=2484 \mathrm{smp} / \mathrm{jam}$

Kapasitas (C)

Faktor pertumbuhan arus lalulintas

Tahun rencana

$$
=4104 \mathrm{smp} / \mathrm{jam}
$$

(i) $=8,3 \%$

Maka;

(n) $\quad=1$

Volume arus lalulintas tahun rencana $(\mathrm{Pn})=$

$\mathrm{Pn} \quad=\mathrm{Po}(1+\mathrm{i})^{\mathrm{n}}$

$$
\begin{aligned}
& =2484 \times(1+0,083)^{1} \\
& =2690,17 \mathrm{smp} / \mathrm{jam}
\end{aligned}
$$

Untuk menghitung Derajat Kejenuhan $(\mathrm{DS})=$

$\mathrm{DS}=\mathrm{Pn} / \mathrm{C}$

$$
\begin{aligned}
& =2690,17 / 4104 \\
& =0,656
\end{aligned}
$$

Untuk perhitungan selanjutnya dapat dilihat pada Tabel 2 sebagai berikut : 
Tabel 2. Rekapitulasi Prediksi simpang tak bersinyal Jalan MT. Haryono - Jalan Banggeris di Kota Samarinda pada 5 tahun yang akan Datang

\begin{tabular}{|c|c|c|c|c|c|c|}
\hline $\begin{array}{c}\text { Tahun } \\
\text { Ke- }\end{array}$ & $\begin{array}{c}\text { Tahun } \\
\text { Rencana }\end{array}$ & $\begin{array}{c}\text { Vol. } \\
\text { Lalulintas } \\
\text { Tahun Ini }\end{array}$ & $\begin{array}{c}\text { Faktor } \\
\text { Pertumbuhan } \\
\text { Arus Lalulintas }\end{array}$ & $\begin{array}{c}\text { Vol. Lalulintas } \\
\text { Tahun Rencana }\end{array}$ & Kapasitas & $\begin{array}{c}\text { Derajat } \\
\text { Kejenuhan }\end{array}$ \\
\hline & (n) & $($ Po) & $(\mathrm{i})$ & $(\mathrm{Pn})$ & $(\mathrm{C})$ & (DS) \\
\hline 0 & 2019 & 2484,00 & 0,083 & 2484,00 & 4104,00 & 0,605 \\
\hline 1 & 2020 & 2484,00 & 0,083 & 2690,17 & 4104,00 & 0,656 \\
\hline 2 & 2021 & 2484,00 & 0,083 & 2913,46 & 4104,00 & 0,710 \\
\hline 3 & 2022 & 2484,00 & 0,083 & 3155,27 & 4104,00 & 0,769 \\
\hline 4 & 2023 & 2484,00 & 0,083 & 3417,16 & 4104,00 & 0,833 \\
\hline 5 & 2024 & 2484,00 & 0,083 & 3700,79 & 4104,00 & 0,902 \\
\hline
\end{tabular}

Sumber : Hasil analisis

Berdasarkan hasil rekapitulasi prediksi kemampuan persimpangan simpang tak bersinyal Jalan MT. Haryono - Jalan Banggeris di Kota Samarinda pada 5 (lima) tahun yang akan datang pada Tabel 2, kinerja persimpangan pada Tahun 2019 harus dilakukan perbaikan rekayasa lalu lintas karena derajat kejenuhan rasio v/c $=0,833>0,85$ dengantingkat pelayanan mendekati D atau Arus stabil, kecepatan dikontrol oleh arus lalu lintas, pengemudi dibatasi dalam memilih kecepatan.

\section{Kesimpulan}

\section{PENUTUP}

Berdasarkan hasil analisisi evaluasi simpang tak bersinyal Jalan MT. Haryono Jalan Banggeris di Kota Samarinda menggunakan Software KAJI dapat disimpulkan sebagai berikut :

1. Analisis volume lalu lintas menurut hasil data survei volume lalu lintas jam puncak simpang tak bersinyal Jalan MT. Haryono - Jalan Banggeris di Kota Samarinda adalah

- Keluar dari lengan Timur : 2745 Kendaraan/jam

- Keluar dari lengan Barat : 2539 Kendaraan/jam

2. Perhitungan kinerja simpang tak bersinyal Jalan MT. Haryono - Jalan Banggeris di Kota Samarinda, terdiri dari:

- $\operatorname{Kapasitas}(\mathrm{C})$

:4104 smp/jam

- Derajat kejenuhan

$: 0,605<0,85$

- Tundaan Simpang Minor

$: 9,54<(5,1-15,0)$ artinya Baik

- Tundaan Simpang Mayor $: 5,35<(5,1-15,0)$ artinya Baik

3. Hasil analisis tingkat pelayanan (level of service/LOS) simpang tak bersinyal pada Jalan MT. Haryono - Jalan Banggeris, Rasio v/c : 0,605, berdasarkan tabel tingkat pelayanan dari Morlok maka pada kinerja eksisting simpang tak bersinyal Jalan MT. Haryono - Jalan Banggeris di Kota Samarinda, didapat $\mathrm{v} / \mathrm{c}=0,605<0,85$ mempunyai tingkat pelayanan $(\mathrm{LOS})=\mathrm{C}$, dimana arus stabil, kecepatan dikontrol oleh arus lalu lintas, pengemudi dibatasi dalam memilih kecepatan. 
4. Hasil analisis prediksi kinerja dan tingkat pelayanan (level of service/LOS) simpang tak bersinyal Jalan MT. Haryono - Jalan Banggeris di Kota Samarinda kondisi 5 (lima) tahun yang akan datang adalah

- Arus Lalu lintas (Q) : : $\quad$ :3700,79 smp/jam

- Kapasitas (C) : : : $\quad$ :

- Derajat kejenuhan : :0,902

- Tingkat pelayanan (level of service/LOS), Rasio v/c :0,902 > 0,85 artinya LOS berada di E, dimana Arus tidak stabil, kecepatan terkadang terhenti volume.

\section{Saran}

Adapun saran yang dapat dikemukakan yaitu sebagai berikut :

1. Berdasarkan kinerja lalu lintas tahun 2019 sampai 2024 simpang tak bersinyal Jalan MT. Haryono - Jalan Banggeris di Kota Samarinda, masih dapat menampung volume kendaraan yang lewat tetapi persimpangan ini harus diberi petunjuk atau tanda untuk persimpangan tak bersinyal berupa yield

2. Tingkat pelayanan (level of service/LOS) simpang tak bersinyal rasio v/c : 0,605, maka untuk kendaraan yang melintas di jalan mayor merupakan prioritas untuk melakukan pergerakan, sedangkan jalan minor harus berhatihati dalam melakukan manuver kendaraan.

3. Berdasarkan prediksi analisis untuk 5 tahun kedepan terhadap persimpangan tak bersinyal ini dengan melihat kinerja persimpangan maka harus dilakukan rekayasa lalu lintas dengan beberapa cara dengan pengendalian arus lalu lintas seperti dengan pengalihan arus lalulintas ataupemasangan alat pemberi isyarat lampu lalu lintas (APILL).

\section{DAFTAR PUSTAKA}

1. Adolf D. May, 1990, Traffic Flow Fundamentals, University of California, Berkeley.

2. Ahmad Munawar, 2004, Manajemen Lalu Lintas Perkotaan, "Beta Offset" Jogjakarta

3. C. Jotin Khisty \& B. Kant Kall, 2003, Dasar-Dasar Rekayasa Transportasi, Jilid 1 dan 2, Penerbit Erlangga, Jakarta.

4. Departemen Pekerjaan Umum, 1997, Manual Kapasitas Jalan Indonesia (MKJI), Direktorat Jenderal Bina Marga dan Departemen Pekerjaan Umum, Jakarta.

5. Direktorat Jenderal Perhubungan Darat, 1999, Rekayasa Lalu lintas (Pedoman Perencanaan dan Pengoperasian Lalu lintas di wilayah Perkotaan), Direktorat Bina sistem Lalu lintas dan Angkutan Kota Direktorat Jenderal Perhubungan Darat, Jakarta

6. Hobbs, F.D, 1995, Perencanaan dan Teknik Lalu Lintas, Penerbit Gadjah Mada University Press.

7. McShane, WR. Roess, R.P, 1990, Traffic Engineering, Prentice-Hall, Inc.

8. Morlok, E.K., 1998, Pengantar Teknik dan Perencanaan Transportasi, PenerbitErlangga, Jakarta. 